\title{
Degradation Effects in sc-Si PV Modules Subjected to Natural and Induced Ageing after Several Years of Field Operation
}

\author{
E. Kaplani \\ Mechanical Engineering Dpt, Technological Educational Institute of Patras, Greece
}

Received 10 August 2012; Accepted 17 September 2012

\begin{abstract}
This paper presents ageing effects observed in sc-Si PV modules operating in field conditions for 18 and over 22 years. The effects of both natural ageing processes and induced ageing by external agents, causing partial or total shading of cells for a prolonged period of time, are examined. Optical degradation effects observed through visual inspection include discoloration of the EVA, degradation of the AR coating, degradation of the interface between the cell and encapsulant, corrosion of busbars and fingers, and tears, bubbles and humidity ingress at the back surface of the modules. Thermal degradation effects examined via IR thermography reveal the existence of hot cells, hotspots on the busbars, and colder bubbles. Modules' power and performance degradation is assessed through I-V curve analysis. Results show naturally aged modules to exhibit milder ageing effects than modules subjected to induced ageing, an outcome also supported by their power degradation ratio.
\end{abstract}

Keywords: Natural and induced ageing, IR thermography, I-V curve analysis

\section{Introduction}

PV cell and module ageing is a process which naturally evolves with years of module operation in field conditions. Ageing effects mainly include discolouration of the encapsulant, usually ethylene-vinyl-acetate (EVA) [1], degradation of the anti-reflective (AR) coating, the formation of hotspots [2,3], moisture intrusion, delamination and corrosion [4], cracks, tears and bubbles in the backsheet. Several ageing effects may co-exist even in the same cell and module [5], while optical/ physical, electrical and thermal degradation effects may be linked with, to a lesser or greater degree, power and performance degradation of the module [6,7]. Stronger ageing effects and higher EVA degradation rates are encountered in places of hot and dry climate, with high ambient temperature and UV flux [1,8].

The progression of ageing is generally measured in percentage/ per year, although studies have reported besides linear the possibility for a geometric and exponential progression $[9,10]$. However, due to the complicate nature by which these ageing effects appear, progress, transform and cause further degradation effects, prediction of the exact progression of ageing may be difficult. Nowadays, natural ageing effects in old c-Si modules operating already in fieldconditions for several years may be observed $[6,10,11]$. Stronger ageing effects may be induced by external factors causing continuous or severe damage to the module, including overlaying dust, dirt and bird droppings, surrounding vegetation or fence, causing continuous partial

*E-mail address: ekaplani@teipat.gr

ISSN: 1791-2377 @ 2012 Kavala Institute of Technology. All rights reserved. or total shading and localized temperature increase [12], strong winds and hail causing mechanical shocks, damage of the front glass, back sheet or frame of the module.

Finally, a need for a deeper understanding of the intrinsic ageing mechanisms, the possible extent of degradation, the

effects of ageing on the performance of the module, its power output and energy life, is prominent. This study presents ageing effects in sc-Si PV modules due to natural exposure in field conditions for over 22 years, and induced ageing effects observed in sc-Si modules subjected to external agents accelerating their degradation. Using IR thermography and I-V curve analysis, the results of this study suggest that naturally aged modules exhibit milder ageing effects, more uniformly distributed in all cells of the module, whereas modules subjected to stronger localized induced ageing effects present a non-uniform distribution of both optical and thermal degradation effects, a more distorted I-V curve, and higher power degradation rates.

\section{Experimental Procedure}

Several sc-Si PV modules operating outdoors at the R.E.S. laboratory of T.E.I. of Patras for 18 and 22 years were visually examined for signs of ageing. Six sc-Si PV modules with different optical degradation were selected for further investigation, two of which had been operating outdoors for over 22 years and had undergone only natural ageing processes, and four modules of a different manufacturer operating in field conditions for 18 years, which besides natural ageing were also subjected to induced ageing 
processes for a prolonged period of several months. Induced ageing was caused by partial or total shading invoked by lumps of mortar incidentally shed on the PV array in the past covering a couple of cells in each of these modules, for a prolonged period of several months before it was cleaned. At the time, this created shading and thermal effects in these cells, raising their temperature both due to operation in reverse bias mode as a result of shading and due to higher temperature of the overlaying layer of mortar.

Thermal degradation of these modules was examined via means of IR thermography captured using TROTEC IC080LV thermocamera with detector resolution $384 \times 288$ pixels, accuracy $\pm 2{ }^{\circ} \mathrm{C}$, and spectral range 7.5 to $14 \mu \mathrm{m}$. The performance of these modules was investigated through I-V curve analysis. The I-V curve was captured via means of a portable I-V curve analyser for photovoltaics, with a silicon irradiance sensor with active temperature compensation placed on the same plane as the modules for measuring the irradiance, and a Pt100 sensor placed on the back of the modules for measuring module temperature. Experiments were carried out during the summer period 2012 under clear sky conditions.

\section{Optical Degradation Effects}

Visual inspection of the 22 year old modules revealed severe discoloration of the EVA encapsulant. The discoloration has a golden brown color and is extended to all cells of the modules covering a large part of or even their entire surface. The extent of browning is also visible in the substrate region of the modules (see Fig.1). Studies have reported the discoloration to appear at the central region of the cells having square shape in square cells and circular shape in circular cells [7], something which has been generally observed in these modules. However, certain cells were found to exhibit discoloration in patches or different shapes. EVA discoloration in cells subjected to prolonged shading and thermal effects in the PV modules operating in field conditions for 18 years, displays a brown or dark-brown colour and covers a large part of the cells' surface, as seen in Fig.2. Many naturally aged cells in these modules experience a milder discoloration of the encapsulant with a dark / black colour as seen in Fig.3(b).

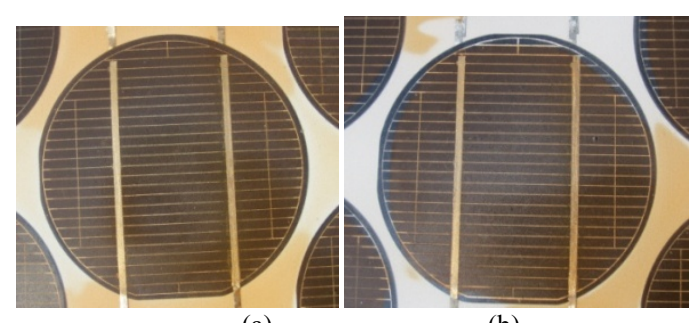

(a)

(b)

Fig.1(a),(b). EVA discoloration in naturally aged sc-Si PV modules operating in field conditions for over 22 years.

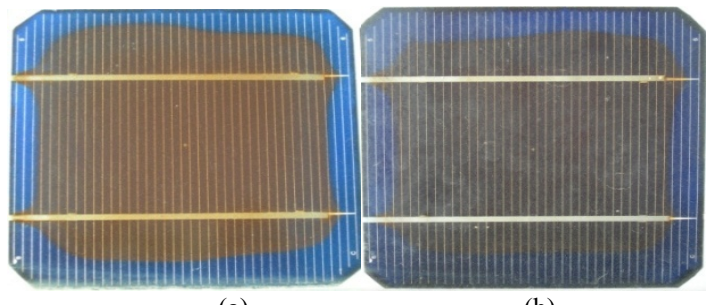

(a)

(b)

Fig. 2(a)(b). EVA discoloration in sc-Si PV cells subjected to severe induced ageing in PV modules operating outdoors for 18 years.
Other degradation effects observed in cells exhibited to only natural ageing processes during the 18 years of field operation include degradation of the AR coating (Fig. 3(a)) and degradation of the interface between the cell and the encapsulant. The latter is usually located between the fingers and close to the busbars as displayed in a worse case in Fig.3(b). Some of the cells subjected to induced shading effects exhibit more severe degradation linked to corrosion of fingers, busbars and contacts (see for eg. Fig.4(a) and 4(b)), which is associated with degradation of the encapsulant [1]. Furthermore, damage in the back sealing of the module was observed, including tear in the Tedlar, bubble, humidity ingress further causing corrosion of the cell metallization, as seen in a severe case in Fig.5.

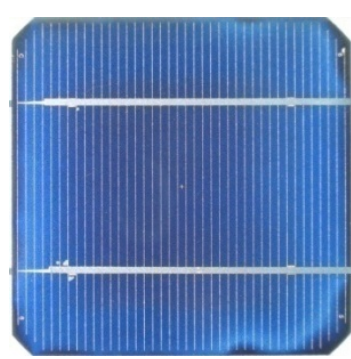

(a)

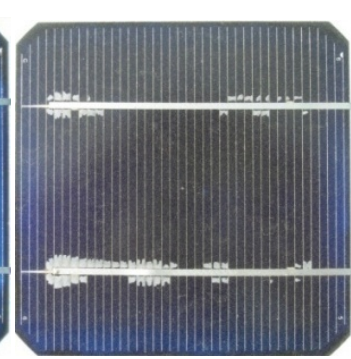

(b)
Fig. 3. Degradation effects in the sc-Si cells of the modules subjected to induced ageing -these cells were not subjected to any shading effects; (a) degradation of the AR coating, (b) degradation of the cellencapsulant interface.

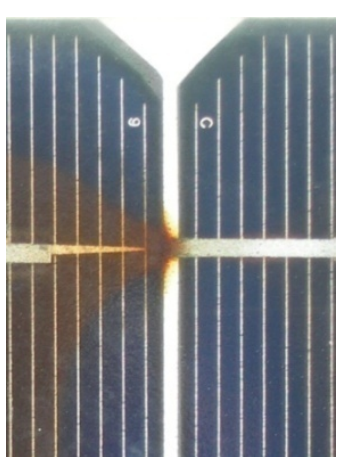

(a)

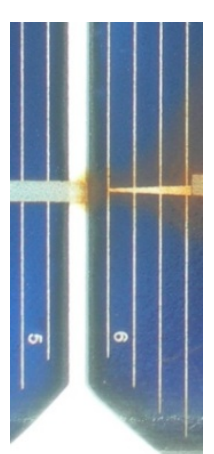

(b)
Fig. 4(a),(b). Corrosion of busbars and contacts in cells subjected to induced shading.

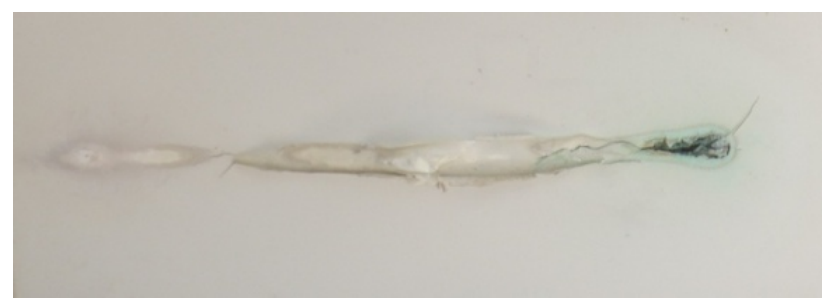

Fig. 5: Damage in the back sealing surface behind the busbar; tear, blister, humidity ingress are visible.

\section{Thermal Degradation}

The temperature distributions of the natural aged modules with over 22 years of field operation (denoted here as modules N1, N2) display a rather uniform temperature distribution with maximum temperature difference between cells of about $10^{\circ} \mathrm{C}$, as seen in Fig. 6. Temperature differences in this range have only a small effect on the power output of the modules, causing only mild mismatch effects. 


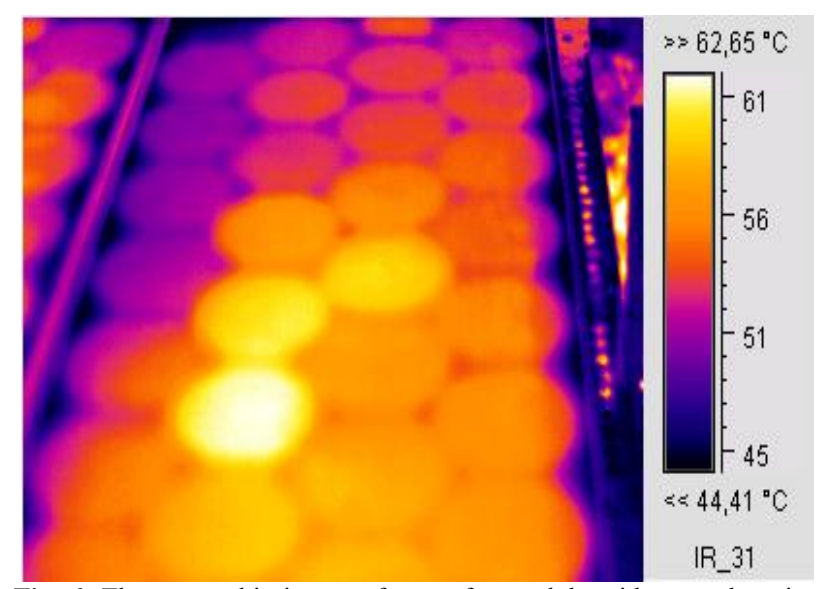

Fig. 6: Thermographic image of part of a module with natural ageing operating in field conditions for over 22 years (module N1).

The IR thermography of the modules subjected to induced ageing (denoted here as modules I1, I2, I3, I4) assists in the determination of the severity of localized cell degradation and the identification of the source of module degradation. The IR thermography of the module with the milder induced ageing effects (module I1) is shown in Fig.7. Temperature difference between cells in this module lies in the range of $10{ }^{\circ} \mathrm{C}$, which would be normally expected in a module operating outdoors for 18 years. The thermographic image of the other modules subjected to more severe induced shading and thermal effects, reveals significantly higher temperatures at the affected cells when compared to the temperature of the remaining cells of the module. Fig. 8 shows the temperature distribution of module $\mathrm{I} 2$ with the severely discoloured cell of Fig.2(a) appearing as a hot cell in the thermography and exhibiting temperature higher by more than $35^{\circ} \mathrm{C}$ compared to the temperature of the remaining cells of the module. Fig. 9 shows the thermoghaphic image of module I3 captured at the back of the cell which suffered induced shading and thermal effects. This cell appears as a hot cell in the thermography, exhibiting hot spots on the top busbar with temperatures higher by about $20^{\circ} \mathrm{C}$ from the temperature of the neighbouring cells of the module.

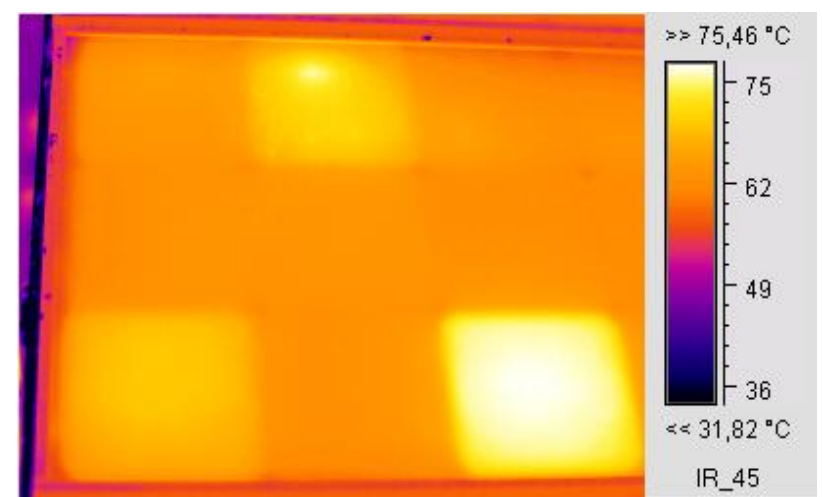

Fig. 7: Thermographic image of part of a module operating in field conditions for 18 years (module I1).

The high localized temperature differences of $20^{\circ}$ and $35^{\circ} \mathrm{C}$ observed cause significant mismatch between neighbouring cells leading to reduction in the current of the module and its power output [13]. It should be noted that even higher temperatures have been observed in these hot cells depending on the incident solar irradiance and ambient temperature at the time of experiment. However, the relative temperature difference between the hot cell and the temperature of the neighbouring cells or the average temperature of the module is of particular concern in order to identify the problematic cell, the extent of the defect, and evaluate the effect of the resulting mismatch.

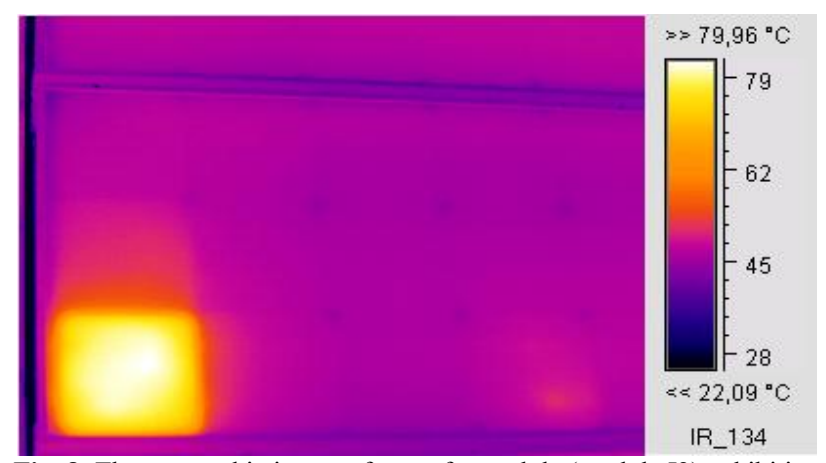

Fig. 8: Thermographic image of part of a module (module I2) exhibiting high temperature at the severely discolored cell (of Fig.2(a)).

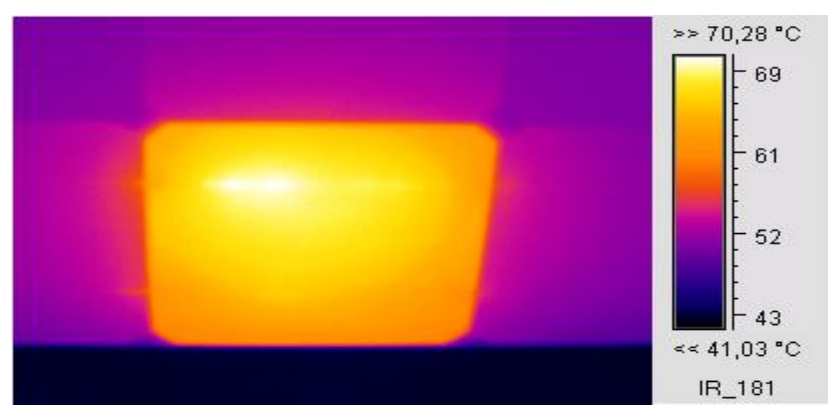

Fig. 9: Thermographic image (from part of module I3) captured from the back of the affected cell revealing hot spots on the bus bar.

The thermographic image of the cell exhibiting severe damage in the back sealing surface at the location of the busbar (see Fig. 5) is displayed in Fig.10. The IR image has been captured at the back side of module I4. A hotspot with extremely high temperature reaching $170^{\circ} \mathrm{C}$ degrees is identified located on the busbar. The tear and blister are also visible having lower temperatures. It may be observed that the temperature of the remaining part of the cell as moving away from the busbar remains as low as that of the average temperature of the module. Such high temperatures are detrimental for the health of the cell, causing degradation in the encapsulant and a chain of chemical reactions leading to further degradation of the cell and module.

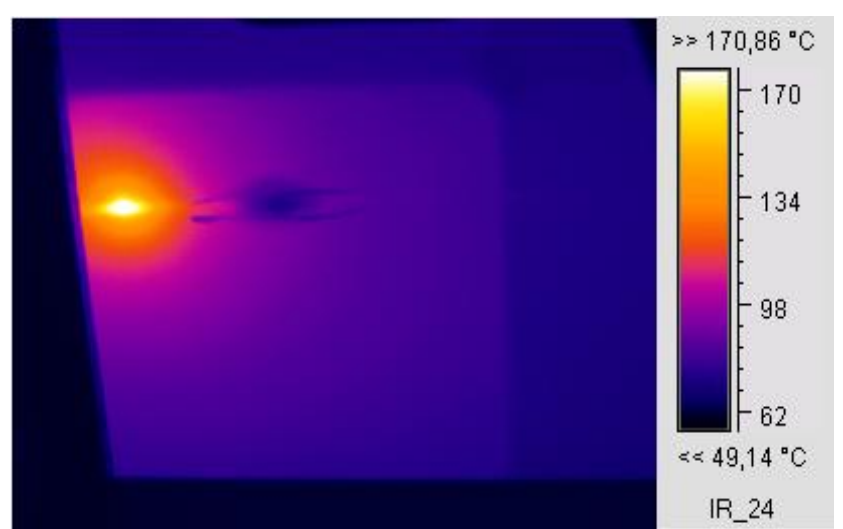

Fig. 10: Thermographic image of the back of the affected cell (of module I4) exhibiting damage in the sealing at the location of the busbar (see Fig.5). 


\section{Performance Degradation}

In order to assess the performance degradation of the PV modules, their electrical characteristics obtained during the $\mathrm{I}-\mathrm{V}$ curve measurements, $I_{s c}^{\prime}, V_{o c}^{\prime}, P_{m}^{\prime}, F F^{\prime}$ were first converted to S.T.C. $\left(\mathrm{AM}=1.5, \mathrm{G}=1000 \mathrm{~W} / \mathrm{m}^{2}, \mathrm{~T}_{\mathrm{c}}=25^{\circ} \mathrm{C}\right)$ based on the following equations $[10,14]$ :

$I_{s c, S T C}^{\prime}=I_{s c}^{\prime} /\left[\left(1+a_{I S C} \cdot\left(T_{c}-25^{0} C\right)\right) \cdot G / 10^{3}\right]$

$V_{o c, S T C}^{\prime}=V_{o c}^{\prime}-\beta_{V o c} \cdot\left(T_{c}-25^{\circ} C\right)-n_{s} \cdot m \cdot k \cdot\left(T_{c}+\right.$ $273) / q \cdot \ln \left(G / 10^{3}\right)$

Prime denotes the current state of the module. Tc is the cell temperature, and $\mathrm{G}$ is the irradiance measured by means of the calibrated reference cell mentioned in the experimental procedure, in order to account for spectral and angle of incidence influences [14].

$\alpha_{\mathrm{Isc}}$ is the temperature coefficient for $\mathrm{I}_{\mathrm{sc}}$ in $1 /{ }^{\circ} \mathrm{C}$ and $\beta_{\mathrm{Voc}}$ is the temperature coefficient for $\mathrm{V}_{\mathrm{oc}}$ in $\mathrm{V} /{ }^{\circ} \mathrm{C} . \mathrm{n}_{\mathrm{s}}$ is the number of cells in series, $\mathrm{m}$ the ideality factor of the diode considered here as 1 ; and $\mathrm{k}$ is the Boltzman constant and $\mathrm{q}$ the electron charge.

According to Anderson's method [15], each point in the I-V curve can be translated to STC using the following equations for each I-V pair:

$I_{S T C}^{\prime}=I^{\prime} \cdot \frac{I_{S c, S T C}^{\prime}}{I_{S C}^{\prime}}$

$V_{S T C}^{\prime}=V^{\prime} \cdot \frac{V_{o c, S T C}^{\prime}}{V_{o c}^{\prime}}$

The maximum power is then translated to STC based on the following equation [15]:

$P_{m, S T C}^{\prime}=P_{m}^{\prime} \cdot \frac{I_{s c, S T C}^{\prime}}{I_{s c}^{\prime}} \cdot \frac{V_{o c, S T C}^{\prime}}{V_{o c}^{\prime}}$

Having translated the $I_{s c}^{\prime}, V_{o c}^{\prime}, P_{m}^{\prime}$ to STC based on eq.(1),(2),(5), the fill factor FF is then translated to STC based on the following expression:

$F F_{S T C}^{\prime}=\frac{P_{m, S T C}^{\prime}}{I_{S c, S T C}^{\prime} \cdot V_{o c, S T C}^{\prime}}$

The performance degradation of the modules may be evaluated qualitatively based on the shape of their I-V curve through the deformations observed or radical changes in module shunt resistance $R_{\text {sh }}$ (through the slope of the I-V curve at $I_{s c}$ ) and series resistance $R_{s}$ (through the slope of the curve at $\mathrm{V}=\mathrm{V}_{\mathrm{oc}}$ ) [10]; and may be quantitatively assessed in terms of reductions in their electrical characteristics when compared to the factory ratings. Two important measures of module degradation are the power degradation measured as the relative change in the peak power $\delta \mathrm{P}_{\mathrm{m}} / \mathrm{P}_{\mathrm{m}}$, and the relative change in the fill factor $\delta \mathrm{FF} / \mathrm{FF}$ as given by the following equations [16]:

$$
\begin{aligned}
& R D_{P m}=\frac{P_{m, S T C}-P_{m, S T C}^{\prime}}{P_{m, S T C}} \cdot 100 \% \\
& R D_{F F}=\frac{F F_{S T C}-F F_{S T C}^{\prime}}{F F_{S T C}} \cdot 100 \%
\end{aligned}
$$

The normalized I-V curves of the modules subjected to induced ageing I1, I2, I3, I4 are displayed in Fig.11. The normalization to STC, as previously described, was carried out based on eqs. (3),(4).

Module I1 subjected to only mild induced ageing effects displays a rather normal I-V curve shape, while deformations in the shape of the I-V curves may be observed for modules I2, I3, I4 which have suffered more severe induced ageing effects (see Fig.11). Module I2 with the severe optical and thermal degradation in one of its cells (see Figs.2(a) and 8), displays a steep stepwise decrease in the I$\mathrm{V}$ curve similar to that caused by a partial shading effect. The I-V curve of module I3, presents a significant decrease in the slope of the curve at $\mathrm{V}_{\mathrm{oc}}$ revealing the existence of a high parasitic series resistance $R_{s}$. This is also supported by the high temperature of the bus bar identified in the IR thermography (see Fig. 9). Both a small current drop and a significantly high parasitic series resistance is revealed through the decreased slope at $\mathrm{V}_{\mathrm{oc}}$ in the $\mathrm{I}-\mathrm{V}$ curve of module I4. The identified source of degradation in this module is the cell behind which severe damage in the back sealing surface appears, shown in Fig.5. Its thermographic image provided in Fig.10 which shows an extreme hot spot located on the bus bar explains the increased series resistance observed through its I-V curve.

Fig. 12 shows the I-V curves of the other two sc-Si modules of different manufacturer (modules N1, N2) which experienced only natural ageing after 22 years of field operation. The shape of their I-V curve is free of severe deformations but gives evidence of a reduced shunt resistance $\mathrm{R}_{\mathrm{sh}}$ as shown by the reduced slope of the curves at $\mathrm{I}_{\mathrm{sc}}$. This is also supported by the relatively uniform optical degradation (see Fig.1) and thermal degradation (see Fig. 6) which these modules experience in all of their cells.

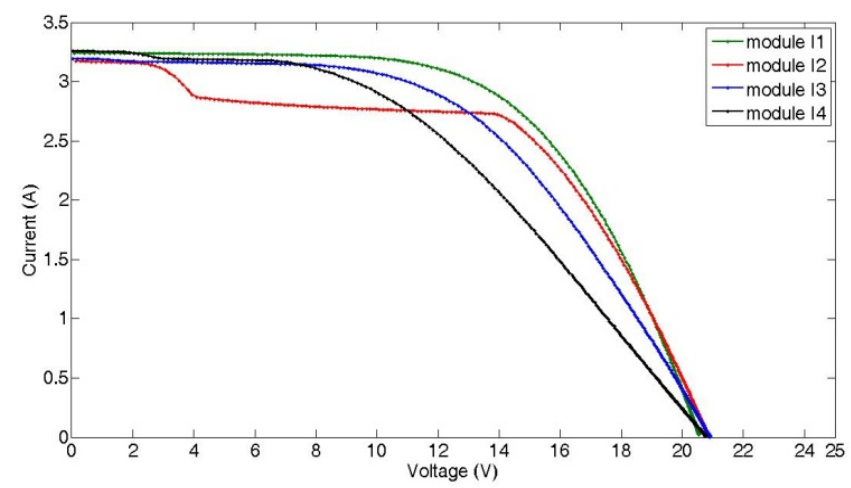

Fig. 11. Normalized I-V curves of modules I1, I2, I3, I4 with induced ageing and field operation of 18 years.

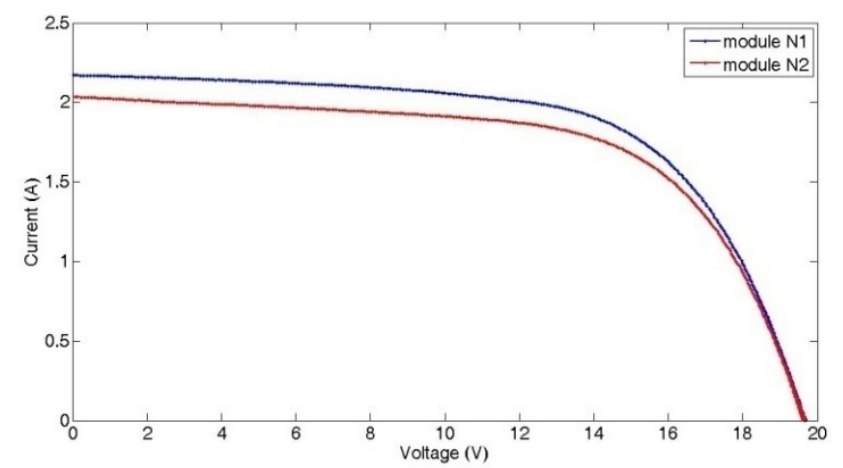

Fig. 12. Normalized I-V curves of modules N1, N2 with natural ageing and field operation of over 22 years. 
The power degradation of the modules and their degradation in terms of the fill factor as determined by eqs.(7) and (8) respectively, are presented in Table 1. The results for modules I1, I2, I3, I4 with induced degradation vary significantly supporting the fact that these modules have indeed suffered different degree of induced degradation and a combination of different ageing effects as also observed in the shape of their I-V curves. Module I1 with the milder induced ageing effects displays a $23.8 \%$ of power degradation in its 18 years of field operation and a smaller degradation in terms of the fill factor of $16.9 \%$, as can be also realized by the rather good shape of its I-V curve (see Fig.11). Modules I2,I3,I4 with more severe induced ageing effects exhibit higher power degradation ranging from $27.6 \%-42.2 \%$ and also high degradation in terms of the fill factor from $20.4 \%-37.8 \%$, which is supported by the deformations in the shape of their I-V curve. Module I2, with the severely discoloured cell (see Fig.2(a)) shares lower power degradation and fill factor rates than modules I 3 and I4 which exhibited increased series resistance (see respective I-V curves in Fig.11) and hotspots on the busbars (see IR thermographies in Figs.9 and 10). This also highlights the different extent and progression of ageing even after similar induced ageing effects. The naturally aged modules $\mathrm{N} 1$ and $\mathrm{N} 2$, display power degradation of $18.3 \%$ and $23.6 \%$ respectively, and in terms of the fill factor lower rates of $11.9 \%$ and $12 \%$ respectively, which is supported by the shape of their I-V curve. The degradation rates of these modules are anticipated considering their over 22 year of field exposure and are supported by their severe optical degradation. Their power degradation rates are smaller or similar to that of the 18 year old module I1, which was however subjected to only mild induced ageing effects, and lower in terms of the fill factor proving better performance despite their increased age.

Table 1. Percentage relative degradation in power output and fill factor for modules with induced and natural ageing.

\begin{tabular}{ccc}
\hline Modula & RJTHm\% & RJPFF\% \\
\hline J1 & 23.8 & 16.9 \\
J2 & 27.6 & 20.4 \\
J3 & 32.6 & 26.7 \\
J4 & 42.2 & 37.8 \\
V1 & 18.3 & 11.9 \\
V2 & 23.6 & 12.0
\end{tabular}

\section{Discussion}

Although the sample is rather small the results clearly indicate a difference between the degradation evolved through natural ageing and induced ageing conditions. The naturally aged modules exhibit milder and more homogenous degradation in terms of optical and thermal effects, and in performance displaying an I-V curve without serious deformations in shape. Visual inspection of the naturally aged modules showed severe discolouration of the encapsulant with a golden brown colour covering a large part of all cells of the module. The discolouration was generally homogenous in both modules. The IR thermography of these modules revealed a homogenous temperature distribution with temperature differences between cells not exceeding $10^{\circ} \mathrm{C}$. Their degradation in performance was basically seen through a reduced shunt resistance $R_{s h}$ in their I-V curve analysis. Their percentage relative degradation in terms of the fill factor reveals mild effects as also supported by the shape of their I-V curve. Their average annual power degradation may be estimated to $0.83 \%$ and $1.1 \%$, which is within the anticipated range.

Module I1, from a different manufacturer, with mild induced ageing effects and 18 years of field operation displayed a rather homogenous optical degradation with milder discoloration assuming though a dark colour and other optical degradation effects linked to AR deterioration and degradation in the cell-encapsulant interface. The IR thermography of this module also revealed a homogenous temperature distribution with maximum temperature difference between cells of about $10^{\circ} \mathrm{C}$. Such small differences in temperature cause only small mismatch effects and can be even encountered in much younger PV modules. Its average annual power degradation is estimated to about $1.3 \%$.

Modules I2, I3, I4 subjected to severe induced ageing conditions for several months during their 18 years of field operation, display severe localized optical degradation in the affected cells, exhibiting severe discolouration of the encapsulant assuming a brown to dark brown colour. In many cases this discolouration is also linked with corrosion of fingers, busbars and contacts as a result of degradation of EVA and the AR coating. The severe EVA discoloration in the affected cells reduces optical transmission leading to losses in $\mathrm{I}_{\mathrm{sc}}$ [1], as particularly observed in module I2. The I$\mathrm{V}$ curve of module I2 shows a large stepwise decrease similar to that caused by partial shading. The IR thermography revealed the existence of hot cells associated to the affected cell in these modules, exhibiting temperatures higher by $20^{\circ}-35^{\circ} \mathrm{C}$ from neighbouring cells and average temperature of module and the existence of extreme hot spots reaching even $170^{\circ} \mathrm{C}$ as in the severe case of module I4 (see Fig.10) which exhibits severe damage in the back of the cell (see Fig.5). Such high temperature differences imply current mismatch between the cells of the same string, with the faulty cell dissipating power within itself in the form of heat. Extremely high temperatures observed in hot spots cause a localized physical degradation of the cell through a combination or chemical reactions caused with degradation of the encapsulant, leading to other ageing effects such as corrosion, bubbles, etc. Of course in cases were corrosion is evident as in the severe case of module I4, a high parasitic series resistance $R_{s}$ is observed through the slope of the I-V curve at $\mathrm{V}_{\mathrm{oc}}$. Such severe induced degradation is shown to lead to permanent deformations in the shape of the I-V curve, and to increased power degradation rates. Modules I2, I3, I4 exhibit increased degradation in terms of performance, fill factor and power output. Estimation of an average annual power degradation rate would not be representative of the normally expected case as it is suspected that the degradation of these modules followed a geometric progression during and after the time they were subjected to induced ageing effects. The complexity of the ageing process and the reactions that take place perhaps indicate that after a certain threshold degradation of the module may change from linear to geometric progression.

\section{Conclusions}

This study has examined six modules from two different manufacturers operating in field conditions for a period of 
18 and over 22 years. The modules with 22 years of field operation were only naturally exposed to field conditions, while modules with 18 years of field operation besides natural ageing were also subjected to severe induced ageing effects for a period of several months. The modules were selected to exhibit different severity of optical degradation and were examined via means of visual inspection, IR thermography and I-V curve analysis. The results of this study suggest that naturally aged modules exhibit milder ageing effects, more uniformly distributed in all the cells of the module, whereas modules subjected to stronger localized induced ageing effects present a non-uniform distribution of both optical and thermal degradation and a more distorted I$\mathrm{V}$ curve, and, finally, much higher power degradation rates. Of course the increased non-uniformity of the temperature distribution is related to the localized accelerated ageing conditions induced, but also to the complex chemical reactions that take place during progression of intense ageing phenomena leading to more severe defects.

Similar induced ageing effects may be encountered in PV field operation at remote sites, or sites of rich vegetation where bird droppings, partial/total shading from nearby objects or fences repeatedly occur. These may lead to more permanent optical and physical cell degradation phenomena. This study has shown some of the extents of optical, physical, thermal and performance degradation in sc-Si PV modules both after normal and incidentally induced ageing during operation in field conditions. This gives rise to the necessity for more delicate handling, transportation, installation and maintenance procedures, and, furthermore for the tele-monitoring of PV

sites with the application of tele-diagnostic techniques for the early detection of faults and induced ageing effects, promoting a healthier and prolonged module energy life.

\section{Acknowledgements}

The project is co-funded by the European Union -European Regional Development Fund and National Resources (NSRF 2007-2013). The author would like to express her appreciation for the funding received. The author would also like to thank Prof. S. Kaplanis, project coordinator and Head of the R.E.S. laboratory, for valuable discussions.

\section{References}

1. A.W. Czanderna, F.J. Pern. "Encapsulation of PV modules using ethylene vinyl acetate copolymer as a pottant: A critical review". Solar Energy Materials and Solar Cells, 43: 101-81, 1996.

2. L. King, J.A. Kratochvil, M.A. Quintana, et al. Applications for infrared imaging equipment in photovoltaic cell, module, and system testing". Photovoltaic Specialists Conference, 2000. Conference Record of the Twenty-Eighth IEEE, pp. 1487-90, 2000. doi: 10.1109/ PVSC.2000.916175.

3. M. Simon, E.L. Meyer. "Detection and analysis of hot-spot formation in solar cells". Solar Energy Materials and Solar Cells, 94: 106-13, 2010.

4. M.A. Quintana, D.L. King, T.J. McMahon et al. "Commonly observed degradation in field-aged photovoltaic modules". Photovoltaic Specialists Conference, 2002. Conference Record of the Twenty-Ninth IEEE, pp. 1436-39, 2002. doi: 10.1109/PVSC.2002.1190879

5. E. Kaplani. "Detection of degradation effects in field-aged c-Si solar cells through IR thermography and digital image processing”. International Journal of Photoenergy, Vol. 2012: Article ID 396792, pp.1-11, 2012. doi:10.1155/2012/396792

6. D. Chianese, A. Realini, N. Cereghetti, et al. "Analysis of weathered c-Si PV modules". $3^{\text {rd }}$ World Conference on Photovoltaic Energy Conversion, May 11-18, Osaka, Japan, 2003.

7. Parretta, M. Bombace, G. Graditi, et al. "Optical degradation of long-term, field-aged c-Si photovoltaic modules". Solar Energy Materials and Solar Cells, 86: 349-64, 2005.

8. J. Schlothauer, S. Jungwirth, M. Koehl, et al. "Degradation of the encapsulant polymer in outdoor weathered photovoltaic modules: Spatially resolved inspection of EVA ageing by fluorescence and correlation to electroluminescence". Solar Energy Materials \& Solar Cells, 102: 75-85, 2012.

9. M. Vazquez, I. Rey-Stolle. "Photovoltaic moduel reliability model based on field degradation studies". Progress in Photovoltaics: Research and Applications, 2008. DOI: 10.1002/pip

10. S. Kaplanis, E. Kaplani. "Energy performance and degradation over 20 years performance of BP c-Si PV modules". Simulation Modelling Practice and Theory, 19: 1201-11, 2011.

11. Skoczek, T. Sample, E.D. Dunlop. "The results of performance measurements of field-aged crystalline silicon photovoltaic modules". Progress in Photovoltaics: Research and Applications, 17: 227-40, 2009.

12. E. Kaplani. "Design and performance considerations in stand-alone PV powered telecommunication systems". Journal of Engineering Science and Technology Review, 5:1, 1-6, 2012.

13. P. Spirito, V. Albergamo. "Reverse bias power dissipation of shadowed or faulty cells in different array configurations". PV Solar Energy Conference. Proc. of $4^{\text {th }}$ Int. Conf., Stresa, Italy, May 1982.

14. D.L. King, W.E. Boyson, J.A. Kratochvil. "Photovoltaic array performance model". SAND2004-3535, Sandia National Laboratories, August 2004.

15. A.J. Anderson. "Photovoltaic translation equations: A new approach", Final Subcontract Report, NREL/TP-411-20279, NREL, January 1996.

16. E. Kaplani, S. Kaplanis. "PV ageing effects and performance degradation of c-Si PV cells", Proc. $6^{\text {th }}$ International Workshop on Teaching in Photovoltaics (IWTPV'12), Czech Republic, 22-23 March, 2012, pp.17-21. 